\title{
Analysis of Adiponectin Levels in Covid-19 Patients and Their Relationship to the Occurrence of Multi-Organ Failure and Mortality
}

\author{
Susy Melanie ${ }^{\mathrm{a}}$, Arie Utariani ${ }^{*}$, Philia Setiawan ${ }^{\mathrm{a}}$, \\ Prananda Surya Airlangga ${ }^{a}$, Edward Kusuma $^{a}$ \\ aDepartment of Anesthesiology and Reanimation, Faculty of Medicine, Universitas \\ Airlangga, Surabaya, 60286, Indonesia
}

*Corresponding Author: arieutariani1955@gmail.com

\begin{abstract}
Chronic inflammation in comorbidities is thought to be the main cause of the low multiorgan dysfunction (MODS) threshold and death. The failure of the immune system's homeostatic feedback loop triggers ongoing inflammatory activation. Beginning with obesity as a pathological beginning of noncommunicable disease (NCD) and deficiency of adiponectin. Which has anti-inflammatory properties, inhibits the secretion and activation of various inflammatory cytokines (TNF-, IL-1, IL-6, and IFN-) and maintains innate immunity.

This is an analytic observational study with a cross-sectional design. The sampling technique is total sampling. The study was conducted in the COVID-19 isolation room at RSUD Dr. Soetomo Surabaya from May to June 2021. Blood samples were taken on day 0 of treatment, with autoanamnesis data and medical records. The normality test uses the Kolmogorv-Smirnov, and Contingency coefficient test was conducted to assess the correlation between nominal type variables.

There were 153 research subjects; MODS was experienced by $82.35 \%$ of subjects, and mortality was experienced by $32.68 \%$. There was a relationship between MODS and mortality $(\mathrm{P}=0.016)$. The median ADP level in the study was $2.8 \mathrm{ng} / \mathrm{mL}$ and was associated with multiorgan failure $(\mathrm{P}=0.047)$ and mortality $(\mathrm{P}=0.019)$. With a cut-off value of $3.15 \mathrm{~g} / \mathrm{mL}$, the ROC ADP area under the curve (AUC) is 0.378 ( $\mathrm{P}=0.048$, CI 0.265-0.491).Length of stay $(\mathrm{LoS})$ and degree of ARDS were significantly related to ADP levels $(\mathrm{P}=0.007$ and $\mathrm{P}=0.004)$.

Initial ADP levels were associated with mortality and MODS. ADP levels are related to LoS and the degree of ARDS, or the initial P/F ratio value.
\end{abstract}

Keywords: adiponectin, comorbidity, mortality, MODS, COVID-19

\section{Introduction}

Corona virus disease 2019 (COVID-19), a respiratory infection caused by the severe acute respiratory syndrome virus corona 2 (SARS-CoV-2), was originated in Wuhan, China, and become a pandemic momentarily.(1) The mortality rate of oid-19 was reported to be $4 \%$ in Shout East Asia.(2) COVID-19 severity was influenced by comorbidities of the patients. The most prevalent comorbidities are hypertension, diabetes mellitus, chronic obstructive pulmonary disease. Approximately, 25.1\% of severe COVID-19 had at least 1 comorbidity and $8.2 \%$ of them had at least 2 comorbidities. Hypertension became the highest comorbidity responsible for the severe COVID-19 manifestation, which accounted for $16.9 \%$, followed by diabetes mellitus in $8.2 \%$.(3)

Obesity was closely correlated with all of those metabolic conditions and became the root of inflammation pathologies and COVID-19 risk of infection.(4) patients with obesity had an increasing demand of physical compliance anatomically from adipose tissue to expand, nevertheless, lack of blood supply and oxygenation leads to chronic 'low-grade' inflammation or meta-inflammation and worse, para-inflammation.(5) Low-grade inflammations chronically trained the innate immunity to immediately activate long-term phenotype after the stimulation, in this circumstances, the cytokines and saturated fatty acid.(6) In obesity, adipose hormones of Adiponectin (ADP) was decreasing and became the stimulant of atherogenic disease, diabetes mellitus, and inflammation. Hypoadiponectinemia was associated with coronary artery disease, type 2 diabetes mellitus, primary hypertension, and metabolic syndromes. SARS-CO-2 infection was correlated with Angiotensin Converting Enzyme-2 (ACE2), which was widey distributed in adipose tissue. (7) Angiotensin II binding with 
AT1 receptor generates the pro-inflammatory and prothrombotic milieu, free radical of reactive oxygen species, fibrosis and pathologic alterations of the cells.(6)

Adiponectin is a hormone and also a cytokine that regulates energy metabolism of glucose and fat, insulin resistance, and homeostasis regulation of immune system and anti-inflammatory agents. Hypoadiponectinemia causes the insulin resistance and dyslipidemia.(8) normal value of Adiponectin is in the range of 3 to $30 \mu \mathrm{g} / \mathrm{ml}$ in a healthy body. Adiponectin prevents oxidative stress, reduces inflammatory cytokines, and lipid levels. Decrease of Adiponectin stimulates the activation of cellular kinases.(5) Therefore, we aimed to investigate Adiponectin (ADP) levels in COVID-19 patients, and the relationship between ADP levels to the incidence of multiorgan dysfunction (MODS) and mortality.

\section{Methods}

2.1 Study design and population

This was an observational prospective analytical study using primary and secondary data to analyse the correlation of serum ADP levels with the incidence of MODs and mortality in COVID-19 patients hospitalized in infection unit. This study was held in infectious unit of Dr. Soetomo Genreal hospital, Surabaya, Indonesia, from May 2021 to June 2021.

We included all adult patients aged $\geq 18$ years old who had COVID-19 confirmed by PCR swab test and who agreed to join this study and signed the informed consent. We excluded patients with uncomplete medical history, patients who died less than 24 hours upon the blood sampling. We also excluded patients who were against medical advice.

\subsection{Variables and measurements}

The independent variable was ADP serum levels in the confirmed COVID-19 patients, and compared to the MODs incidence and mortality as the dependent variable. The potential confounding variables in our study were age, gender, body mass index, and medications history of the patients.

MODs was defined as the organs function impairment in acute disease which causes the incapability to maintain homeostasis without medical intervention, involving $>2$ organ systems. Acute respiratory distress syndrome (ARDS) is an acute condition marked with the P/F ratio of $<300 \mathrm{mmHg}$ with a minimum PEEP of $5 \mathrm{cmH} 2 \mathrm{O}$ from the serial blood gas analysis and chest X-ray. Organ systems that were affected in COVID-19 and were investigated in this research to be determined as the MODs is the respiratory, cardiovascular, central nervous system, and urinary systems, as well as hepatobiliary system.

Respiratory failure could be manifested as ARDS, which is a diffuse and acute disease causing the vascular hyperpermeability, loss of aired lungs, with a marked hypoxia, bilateral opacity, lung oedema relating to the increase of vein admixture and dead space as well as the decrease of lung compliance. Acute cardiovascular spectrums syndrome related to COVID-19 (AcovCS) is a collection of symptomatic cardiovascular disease during hospitalization in those whom without symptoms in the last 3 months or the patients with the increase of cardiac enzymes during the hospitalization. COVID-19 manifestation sin the central nervous system could be the decrease of consciousness, measured with Glasgow Coma scale, presence of cerebrovascular attack without other reason during COVID-19 care in infection unit.

COVID-19 complicated with acute kidney injury was defined as the increase of serum creatinine levels $\geq 0.3$ $\mathrm{mg} / \mathrm{dL}$ in 48 hours or the increase of serum creatinine levels more 1.5 times higher than the normal value, during the last 7 days, or decrease of urinary production $<0.5 \mathrm{ml} / \mathrm{kg} /$ hour in 6 hours. Acute non-specific hepatitis caused the increase of AST twice the normal levels without any secondary conditions. Coagulopathy was marked with the increase in D-dimer levels $(0.5 \mu \mathrm{g} / \mathrm{mL})$ or FDP, thrombocyte $<100.000 / \mathrm{mm} 3$ of TEG results of hypercoagulation and/ or hyperfibrinolysis.

Mortality was determined according to the World Health Definition of mortality in COVID-19 patients.(9) Adiponectin (ADP) is a gelatin-28 (GBP28) binding protein, and was measured by ELISA method in this study.

\subsection{Study Instruments and data collection}

Study subjects was chosen based on the inclusion and exclusion criteria. The eligible patients were explained and asked to sign the informed consent for those who agreed to join the study. Demographical data, anamnesis, physical examinations, were documented in the data collection form. Blood plasma specimen was taken subsequently, using EDTA tube or heparin as the anticoagulant. Blood samples was stored not more than 5 days in the temperature of $2-8^{\circ} \mathrm{C}$ or in the temperature of $-80^{\circ} \mathrm{C}$ for the storage of 6 months. 
Samples were centrifugated 15 minutes with 2000-3000 RPM speed in the temperature of 2-80C for 20 minutes. Reagents and standard solution in the ELISA kit was prepared and $50 \mu 1$ of standard solution was added into the ELISA's well without adding the antibody, followed by the addition of $40 \mu 1$ sample solution, $10 \mu 1$ antibody antiADP and 50 $\mu$ l streptavidin-HRP. The wells were incubated for 60 minutes in $37^{\circ} \mathrm{C}$ and soaked with $0.35 \mathrm{ml}$ of buffer solution for 30 seconds- 1 minutes for each washing. The wells was dried using tissue paper and $50 \mu 1$ of substrate solution was added subsequently, followed by the incubation of 10 minutes in $37^{\circ} \mathrm{C}$ inside a dark room. After that, a stop solution was added 50 $\mu$ lin each well, until the color turned to yellow. Optical density (OD value) from each well was measured using set reader microplate with the wavelength of $450 \mathrm{~nm}$ for 10 minutes.

During the hospitalization, MODs incidence and mortality rate was documented in the data collection form.

\subsection{Statistical analysis}

The collected and documented data were re-checked before analysis and were tabulated and coded. Descriptive analysis was performed for the baseline characteristics of the subjects. Categorical data were displayed with frequency (n) and percentage (\%). Numerical data were identified for the normality using Kolmogorov-Smirnov, with a $\alpha>0,05$ determined to be normally distributed. Numerical data were presented by Mean and Standard deviation (SD). Bivariate analysis was performed using independent t-test for the normally distributed numerical data and Mann-Whitney test for the numerical data which were not normally distributed. The correlation of the variables were analysed using Pearson correlation test (normal distribution) and Spearman (not-normally distributed) or contingency test. A strong correlation was defined if the $r=0,80-1,00$; moderate if the $r=0,60$ 0,799 ; weak if the $r=0,20-0,399$; or very weak if the $r=0,00-1,99$. Statistical program used SPSS.

\section{Results}

3.1 Baseline characteristics of the subjects

Normality of the data was analysed using Kolmogorov-smirnov test, with the significancy of $(\mathrm{P}<0.05)$ in all subjects' characteristics. Chi-squrae / Fisher's exact test was used to compare the differences of the subjects' characteristics towards MODs incidence and mortality, with the significance value of $\mathrm{P}<0.05$. Study participants were mostly male, and BMI ranged from $18.6-24.9 \mathrm{~kg} / \mathrm{m} 2$, and $\mathrm{P} / \mathrm{F}$ ratio $100-199$. BMI and $\mathrm{P} / \mathrm{F}$ ratio variables were significantly correlated to the MODs incidence and the mortality rate.

Variables related to the MODs incidence were the duration of hospitalization $(\mathrm{P}=0.001)$, dyspnea duration before hospital admission $(\mathrm{P}<0.001)$, SOFA score $(\mathrm{P}<0.001)$, albumin levels $(\mathrm{P}=0.026)$ and ADP levels $(\mathrm{P}=0.047)$. Mortality was significantly correlated to the albumin levels $(\mathrm{P}=0.001)$, ADP $(\mathrm{P}=0.019)$, SOFA score $(\mathrm{P}<0.001)$, and the length of stay $(\mathrm{P}<0.001)$.

Table 1. Baseline Characteristics of the subjects

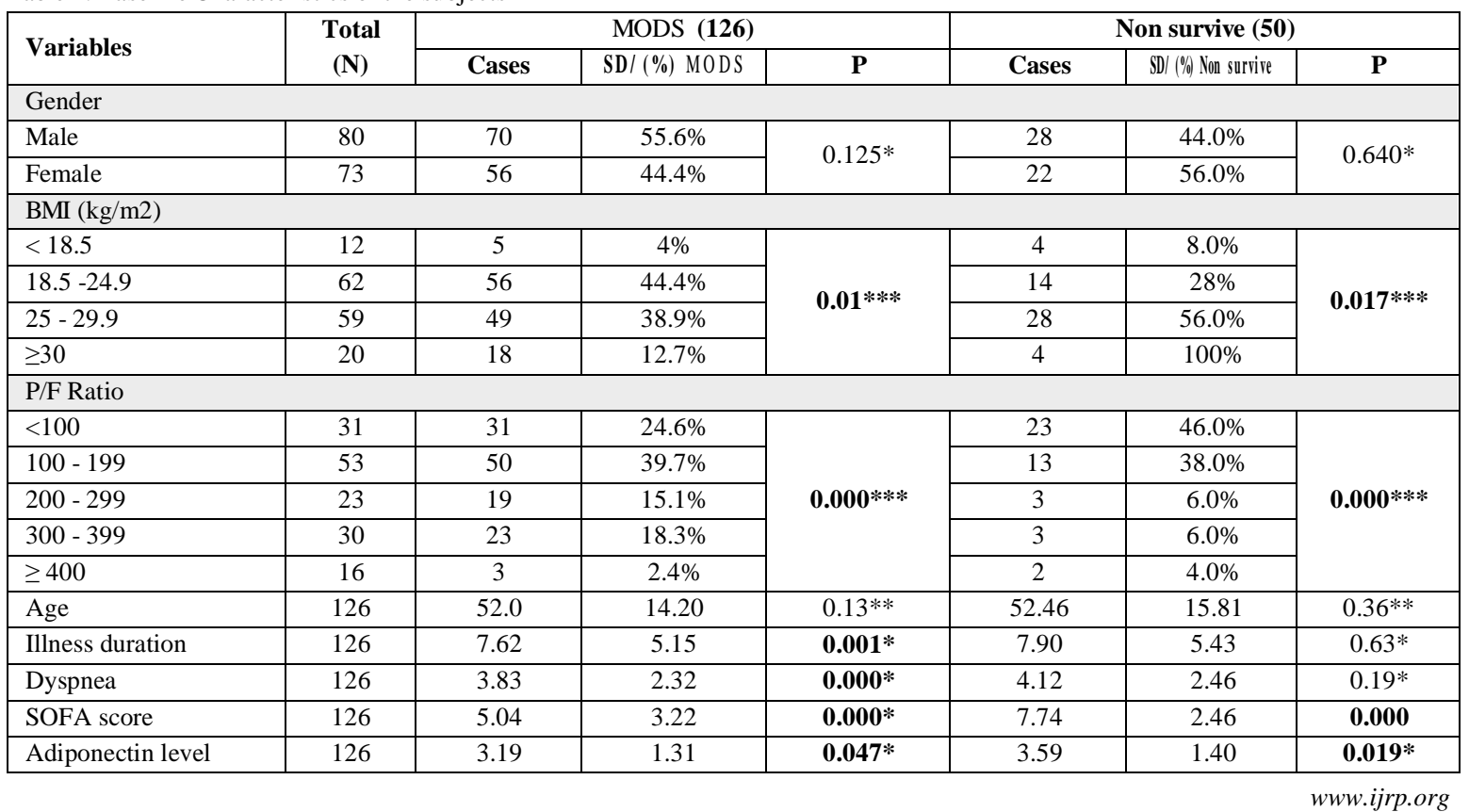




\begin{tabular}{|c|c|c|c|c|c|c|c|}
\hline Albumin & 126 & 2.95 & 0.39 & $0.026 *$ & 2.82 & 0.40 & $0.001 * *$ \\
\hline Length of stay & 126 & 15.6 & 11.07 & $0.12 *$ & 8.32 & 6.31 & 0.000 \\
\hline \multicolumn{8}{|l|}{ Comorbidities } \\
\hline Diabetes & 78 & 72 & $57.1 \%$ & $0.002 *$ & 30 & $60.0 \%$ & $0.167 *$ \\
\hline Tiroid & 3 & 3 & $2.4 \%$ & $1.000^{* *}$ & 2 & $4.0 \%$ & $0.249^{* *}$ \\
\hline Dislipidemia & 51 & 45 & $35.7 \%$ & $0.261 *$ & 20 & $40.0 \%$ & $0.300^{*}$ \\
\hline Hematologi & 62 & 52 & $41.3 \%$ & $0.849^{*}$ & 24 & $48.0 \%$ & $0.256^{*}$ \\
\hline Hipertensi & 83 & 70 & $55.6 \%$ & $0.625^{*}$ & 24 & $48.0 \%$ & $0.364 *$ \\
\hline Stroke & 15 & 12 & $9.5 \%$ & $0.730 * *$ & 5 & $10.0 \%$ & $1.000^{* *}$ \\
\hline DVT & 4 & 3 & $2.4 \%$ & $0.544 * *$ & 2 & $4.0 \%$ & $0.597 * *$ \\
\hline Aritmia & 6 & 4 & $3.2 \%$ & $0.286^{* * *}$ & 2 & $4.0 \%$ & $1.000^{* * *}$ \\
\hline HHD & 59 & 48 & $38.1 \%$ & $0.969^{*}$ & 17 & $34.0 \%$ & $0.528^{*}$ \\
\hline $\mathrm{CAD}$ & 17 & 16 & $12.7 \%$ & $0.310^{* *}$ & 8 & $16.0 \%$ & $0.184 * *$ \\
\hline Penyakit paru menahun & 34 & 28 & $22.2 \%$ & $1.000^{*}$ & 10 & $20.0 \%$ & $0.800^{*}$ \\
\hline Penyakit ginjal menahun & 48 & 42 & $33.3 \%$ & $0.368^{*}$ & 21 & $42.0 \%$ & 0.048* \\
\hline Autoimun & 14 & 10 & $7.9 \%$ & $0.274 * *$ & 4 & $8.0 \%$ & $0.750 * *$ \\
\hline Penyakit hepar menahun & 24 & 21 & $16.7 \%$ & $0.573^{* *}$ & 6 & $12.0 \%$ & $0.524^{* *}$ \\
\hline Keganasan & 18 & 11 & $8.7 \%$ & $0.02 * *$ & 4 & $8.0 \%$ & $0.460^{*}$ \\
\hline Trauma & 9 & 6 & $4.8 \%$ & $0.197^{* *}$ & 1 & $2.0 \%$ & $0.273^{* *}$ \\
\hline Infeksi sekunder & 3 & 2 & $1.6 \%$ & $0.444 * *$ & 2 & $4.0 \%$ & $0.249 * *$ \\
\hline Hamil & 11 & 8 & $6.3 \%$ & $0.411^{* *}$ & 4 & $8.0 \%$ & $0.750^{* *}$ \\
\hline \multicolumn{8}{|l|}{ Medications } \\
\hline Steroid & 6 & 5 & $3.96 \%$ & $1.000^{* *}$ & 1 & $2 \%$ & 0.682 \\
\hline Imunodepresan & 4 & 2 & $1.58 \%$ & $0.144 * *$ & 0 & $0 \%$ & 0.304 \\
\hline Insulin & 5 & 5 & $3.96 \%$ & $0.587 * *$ & 1 & $2 \%$ & 1.000 \\
\hline sulfonilurea & 3 & 2 & $1.58 \%$ & $0.444 * *$ & 0 & $0 \%$ & 0.551 \\
\hline Metformin & 6 & 6 & $4.76 \%$ & $0.591 * *$ & 1 & $2 \%$ & 0.664 \\
\hline Thiazolidines & 2 & 1 & $0.79 \%$ & $0.323 * *$ & 0 & $0 \%$ & 1.000 \\
\hline Antilipid & 3 & 3 & $2.38 \%$ & $1.000^{* *}$ & 1 & $2 \%$ & 1.000 \\
\hline Fibrate & 0 & 0 & $0 \%$ & - & 0 & $0 \%$ & - \\
\hline ACEI / ARB & 14 & 13 & 10.3 & $0.466^{* * *}$ & 2 & $4 \%$ & 0.147 \\
\hline
\end{tabular}

Notes: DVT $=$ deep vein thrombosis; HHD $=$ hipertensive heart disease, CAD $=$ Coronary artery disease; $*$ Uji continuity correction, $* *$ Fisher's exact, ****Pearson chi-square.

Comorbidities and medications data were not normally distributed, and Kolmogorov-smirnov was used to test it. Diabetes mellitus and malignancy had a strong correlation to the MODs incidence $(\mathrm{P}=0.002$ and $\mathrm{P}=0.02$, respectively). Chronic kidney disease (CKD) was the only comorbid that was correlated to the mortality ( $\mathrm{P}=$ 0.048). None of the medications was significantly correlated to mortality.

3.2 Characteristics distribution and their correlation to the Adiponectin levels

The Area under curve (AUC) of ROC in ADP level was 0.378. ADP levels as the predictor of MODs incidence showed a high false positive result $(\mathrm{P}=0.048$; $\mathrm{CI} 0.265$-0.491). The cut-off value of ADP levels in predicting the MODs incidence was $3.15 \mu \mathrm{g} / \mathrm{mL}$. 


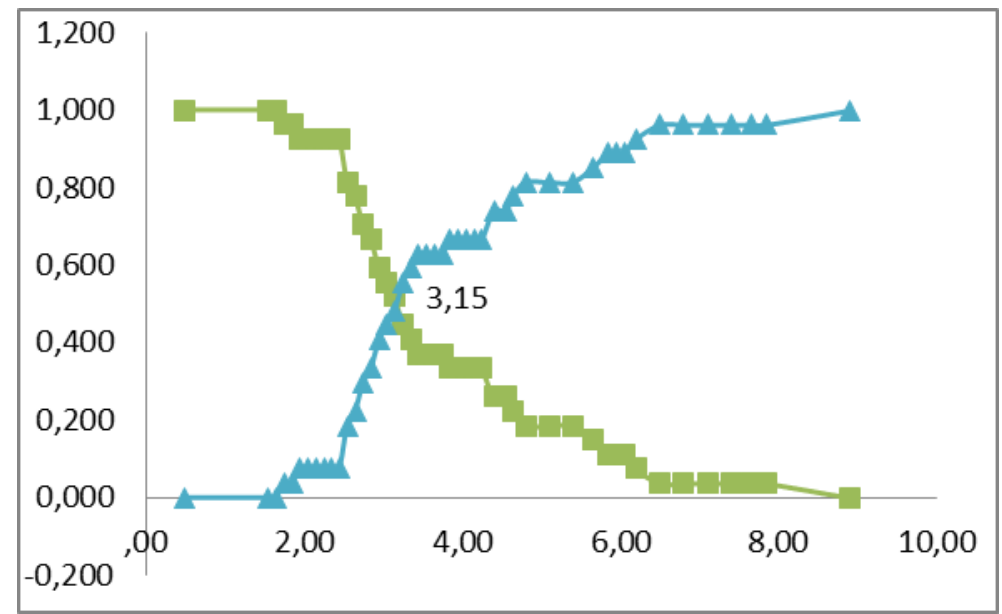

Fig.1. ADP levels cut-off of the sensitivity and specificity in predicting MODs incidence

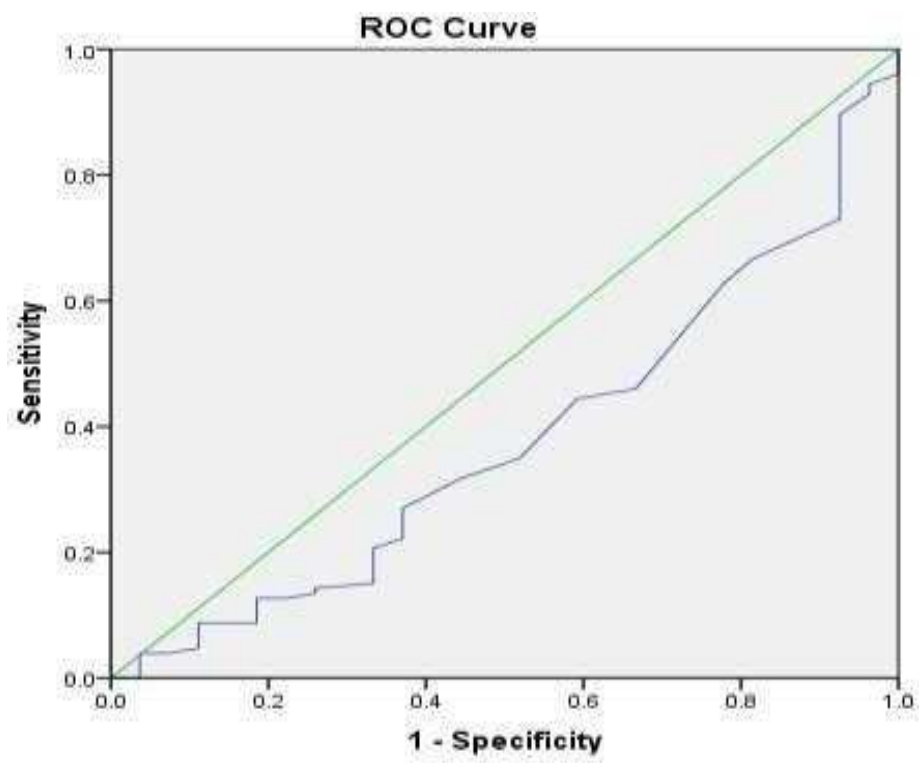

Fig.2. ROC curve of ADP levels in predicting MODs incidence

Patients with the ADP levels $<3.15 \mu \mathrm{g} / \mathrm{mL}$ had a significant difference in the variables of $\mathrm{P} / \mathrm{F}$ ratio, ARDS incidence, outcome, and the length of stay, compared to patients whose ADP levels was $\geq 3.15 \mu \mathrm{g} / \mathrm{mL}$.

Table 2 Frequency distribution of patients' characteristics toward the ADP levels

\begin{tabular}{|c|c|c|c|c|c|c|}
\hline \multirow{2}{*}{ Characteristics } & \multirow{2}{*}{ Total } & \multicolumn{2}{|c|}{$\mathrm{ADP}<3.15 \mu \mathrm{g} / \mathrm{mL}(95)$} & \multicolumn{2}{|c|}{$\mathrm{ADP} \geq 3.15 \mu \mathrm{g} / \mathrm{mL} \mathrm{(58)}$} & \multirow{2}{*}{$\mathbf{P}$} \\
\hline & & $\mathbf{N}$ & $\%$ ADP & $\mathbf{N}$ & $\%$ ADP & \\
\hline \multicolumn{6}{|l|}{ Gender } & \multirow{3}{*}{$0.164 *$} \\
\hline Female & 73 & 50 & 52.6 & 23 & 39.7 & \\
\hline Male & 80 & 45 & 47.4 & 35 & 60.3 & \\
\hline \multicolumn{6}{|l|}{ Age (years) } & \multirow{4}{*}{$0.263 * *$} \\
\hline $17-44$ & 51 & 31 & 32.6 & 20 & 34.5 & \\
\hline $45-64$ & 69 & 47 & 49.5 & 22 & 37.9 & \\
\hline$\geq 65$ & 33 & 17 & 17.9 & 16 & 27.6 & \\
\hline \multicolumn{6}{|l|}{ BMI $\left(\mathrm{kg} / \mathrm{m}^{2}\right)$} & \multirow{5}{*}{$0.497 * *$} \\
\hline$<18.5$ & 12 & 8 & 8.4 & 4 & 6.9 & \\
\hline $18.5-24.9$ & 62 & 34 & 35.8 & 28 & 48.3 & \\
\hline $25-29.9$ & 59 & 40 & 42.1 & 19 & 32.8 & \\
\hline$>30$ & 20 & 13 & 13.7 & 7 & 12.1 & \\
\hline \multicolumn{6}{|l|}{$\mathrm{P} / \mathrm{f}$ ratio } & \multirow{2}{*}{$0.047 * *$} \\
\hline$<100$ & 31 & 14 & 14.7 & 17 & 29.3 & \\
\hline
\end{tabular}




\begin{tabular}{|c|c|c|c|c|c|c|c|}
\hline $100-199$ & 53 & 36 & 37.9 & 17 & & 29.3 & \\
\hline $200-299$ & 23 & 18 & 18.9 & 5 & & 8.6 & \\
\hline $300-399$ & 30 & 20 & 21.1 & 10 & & 17.2 & \\
\hline$\geq 400$ & 16 & 7 & 7.4 & 9 & & 15.5 & \\
\hline \multicolumn{7}{|l|}{ ARDS } & \multirow{5}{*}{$0.004 * *$} \\
\hline Tidak & 16 & 7 & 7.4 & 9 & & 15.5 & \\
\hline Mild & 32 & 22 & 23.2 & 10 & & 17.2 & \\
\hline Moderate & 54 & 42 & 44.2 & 12 & & 20.7 & \\
\hline Severe & 51 & 24 & 25.3 & 27 & & 46.6 & \\
\hline \multicolumn{7}{|l|}{ Albumin (gr/dL) } & \multirow{3}{*}{$0.631 *$} \\
\hline$<3.15$ & 96 & 58 & 63.7 & 38 & & 69.1 & \\
\hline$>3.15$ & 50 & 33 & 36.3 & 17 & & 30.9 & \\
\hline \multicolumn{7}{|l|}{ Outcome } & \multirow{3}{*}{$0.007 * *$} \\
\hline Survive & 103 & 72 & 75.78 & 31 & & 53.44 & \\
\hline Non survive & 50 & 23 & 24.21 & 27 & & 46.55 & \\
\hline \multirow[t]{2}{*}{ Characteristics } & \multicolumn{3}{|c|}{$\mathrm{ADP}<3.15 \mu \mathrm{g} / \mathrm{mL}(95)$} & \multicolumn{3}{|c|}{$\mathrm{ADP} \geq 3.15 \mu \mathrm{g} / \mathrm{mL}(58)$} & \multirow{2}{*}{$\mathbf{P}$} \\
\hline & R a n g e & Median & Mean & Range & Median & mean & \\
\hline Lama sakit (hari) & $0-30$ & 7.00 & $7.24 \pm 7.00$ & $0-33$ & 7.00 & $7.71 \pm 7.03$ & $0.800 * * *$ \\
\hline Gejala Sesak (hari) & $0-8$ & 3.00 & $3.40 \pm 2.25$ & $0-12$ & 3.50 & $3.34 \pm 2.73$ & $0.691 * * *$ \\
\hline SOFA score & $0-10$ & 3.00 & $4.06 \pm 2.99$ & $0-12$ & 5.00 & $5.29 \pm 3.56$ & $0.052 * * *$ \\
\hline LoS (hari) & $2-50$ & 13.00 & $16.4 \pm 11.18$ & $1-47$ & 10.00 & $12.02 \pm 9.7$ & $0.007 * * *$ \\
\hline
\end{tabular}

notes: * continuity correction test, ** Pearson Chi-Square test,

***NPar / Mann-Whitney U test.

Table 3. Frequency distribution and the correlation of comorbidities toward the ADP levels

\begin{tabular}{|c|c|c|c|c|c|c|}
\hline \multirow{2}{*}{ Comorbidities } & \multirow{2}{*}{ Total } & \multicolumn{2}{|c|}{$\mathrm{ADP}<3.15 \mu \mathrm{g} / \mathrm{dL}(95)$} & \multicolumn{2}{|c|}{$\mathrm{ADP} \geq 3.15 \mu \mathrm{g} / \mathrm{dL}(58)$} & \multirow{2}{*}{$\mathbf{P}$} \\
\hline & & $\mathbf{N}$ & $\operatorname{ADP}(\%)$ & $\mathbf{N}$ & ADP (\%) & \\
\hline Diabetes & 78 & 45 & 47.4 & 33 & 56.9 & $0.329 *$ \\
\hline Thyroid disease & 3 & 0 & 0 & 3 & 5.2 & $0.053 * *$ \\
\hline Dislipidemia & 51 & 31 & 32.6 & 20 & 34.5 & $0.953^{*}$ \\
\hline Hematology & 62 & 41 & 43.2 & 21 & 36.2 & $0.497 *$ \\
\hline Hypertension & 83 & 50 & 52.6 & 33 & 56.9 & $0.729 *$ \\
\hline Stroke & 15 & 11 & 11.6 & 4 & 6.9 & $0.506^{*}$ \\
\hline DVT & 4 & 1 & 1.1 & 3 & 5.2 & $0.153 * *$ \\
\hline Arrhythmia & 6 & 3 & 3.2 & 3 & 5.2 & $0.674 * *$ \\
\hline $\begin{array}{l}\text { Hypertensive heart } \\
\text { disease }\end{array}$ & 59 & 35 & 36.8 & 24 & 41.4 & $0.698 *$ \\
\hline Coronary artery disease & 17 & 12 & 12.6 & 5 & 8.6 & $0.617^{*}$ \\
\hline COPD & 34 & 22 & 23.2 & 12 & 20.7 & $0.876^{*}$ \\
\hline CKD & 48 & 30 & 31.6 & 18 & 31.0 & $1.000^{*}$ \\
\hline Chronic liver diasease & 24 & 17 & 17.9 & 7 & 12.1 & $0.464 *$ \\
\hline Autoimunity & 14 & 9 & 9.5 & 5 & 8.6 & $1.000^{*}$ \\
\hline Malignancy & 18 & 10 & 10.5 & 8 & 13.8 & $0.762 *$ \\
\hline Trauma & 9 & 7 & 7.4 & 2 & 3.4 & $0.484 * *$ \\
\hline Secondary infections & 3 & 2 & 2.1 & 1 & 1.7 & $1.000 * *$ \\
\hline Pregnancy & 11 & 8 & 8.4 & 3 & 5.2 & $0.535^{* *}$ \\
\hline \multirow[t]{2}{*}{ Medications } & \multirow{2}{*}{ Total } & \multicolumn{2}{|c|}{ ADP $<3.15 \mu \mathrm{g} / \mathrm{dL}(95)$} & \multicolumn{2}{|c|}{$\mathrm{ADP} \geq 3.15 \mu \mathrm{g} / \mathrm{dL}(58)$} & \multirow{2}{*}{$\mathbf{P}$} \\
\hline & & $\mathbf{N}$ & ADP (\%) & $\mathbf{N}$ & $\operatorname{ADP}(\%)$ & \\
\hline Steroid & 6 & 5 & 16.7 & 1 & 1.7 & $0.409 * *$ \\
\hline Imunosupressant & 4 & 3 & 3.2 & 1 & 1.7 & $1.000 * *$ \\
\hline Insulin & 5 & 1 & 1.10 & 4 & 6.9 & $0.069 * *$ \\
\hline sulfonilurea & 3 & 1 & 1.1 & 2 & 3.4 & $0.558 * *$ \\
\hline Metformin & 6 & 2 & 2.1 & 4 & 6.9 & $0.201 * *$ \\
\hline Thiazolidines & 2 & 1 & 1.1 & 1 & 1.7 & $1.000 * *$ \\
\hline Antilipid & 3 & 3 & 3.2 & 0 & 0 & $0.289 * *$ \\
\hline Fibrate & 0 & 0 & 0 & 0 & 0 & - \\
\hline ACEI / ARB & 14 & 10 & 10.5 & 4 & 6.9 & $0.641^{*}$ \\
\hline
\end{tabular}

$\mathrm{P}<0.05, *$ Uji continuity correction, ** Fisher's exact, ***Pearson chi-square. 
There was no correlation between comorbidities and medications with their ADP levels $(\mathrm{P}>0.05)$.

\section{Discussion}

Most of the patients had the BMI range of $18.5-24.9 \mathrm{~kg} / \mathrm{m} 2$, and with the highest frequency of mortality found in the BMI group of $25-29.9 \mathrm{~kg} / \mathrm{m} 2$ (overweight). There was a significant correlation of the BMI range with the MODs incidence and mortality. This results were supported by the study from Cao et.al., 2021(10) that the risk of septic shock and mortality was 1.04 times higher by the increasing of BMI. The severity of the disease was also increased alongside with overweight and obesity, from 1.84 in overweight into 3.4 times higher in obesity. The median levels of ADP was $2.8 \mu \mathrm{g} / \mathrm{mL}$ in our study; on the contrary, another study stated that the average ADP levels in COVID-19 patients was $14.8 \mu \mathrm{g} / \mathrm{mL}$.(11). In our study age was not correlated with the ADP levels significantly.

Normally, ADP hormone is circulating in 3 forms: HMW (80\%), hexameric $(<10 \%)$, and trimeric $(<10 \%)$. In female group, ADP in HMW and LMW are distributed homogenously, whereas in LMW is dominant in male, thus the ADP level looks like to be higher in female. Our study showed a different result that the ADP levels were not correlated to gender differences. The two conclusions above are in accordance with the results of study by Poehls et al. (2009) with her study (Health ABC study)(12).

In the acute inflammation reaction such in COVI-19 infection, HMW is degraded into the active trimeric form to overcome the acute inflammation. Dissociation of the ADP could be not detected by the conventional device that only could measure the LMW form of ADP and the total ADP. Female tends to respond the inflammation faster ant intensely thus making the faster degradation of ADP too, and affecting the MODs incidence and mortality rate which were relatively lower compared to those in the male.(13)

Adipose tissue had a high expression of ACE2 especially in white adipose tissue (WAT). SARS-COV-2 binding to ACE2 receptor causes the increasing levels of Angiotensin II. Angiotensin II subsequently binds to AT1 receptor and stimulate prothrombotic and pro-inflammatory conditions as well as cell growth, Reactive oxygen species production (ROS) and fibrosis. ADP degradation to its active trimeric form will overcome the inflammation response and the exposure of TNF- $\alpha$, IL-6 /sIL-6R, IL-1b and IFN- $\gamma$ which in long-term period could suppress the total ADP levels secretion (delipidizing adipocytes).(14) A decrease in ADP levels in the beginning of infection was also proved by Hillebrand, et. al (2016).(15)

Our study showed that although there were significant differences between ADP levels in patients with MODs and non-survivor patient, but ADP levels could not predict the MODs incidence in COVID-19 patients (AUC= $0.378, \mathrm{P}=0.048,95 \%$ CI $0.265-0.491)$. ADP levels was measured upon admission and might be different if it was followed-up as the serial measurement of ADP levels in COVID-19 patients. A case control study investigated that Adiponectin levels were significantly lower in patients with COVID-19 respiratory failure, even after adjustment for age, sex, BMI, and other covariates.(16) Another study observing the correlation of ADP in COVID-19 infection showed that ADP level was indeed higher in COVID-19 patients with severe manifestation compared to patients with moderate to severe illness, but was not statistically significant, ADP level was strongly correlated with the increase of IL-6, ceramides, glycerophospholipids, which represented the mobilization of ADP from the adipose tissue to counteract the inflammation.(17)

The continuity correction test in our analysis showed a relationship between COVID-19 patients' outcome (survive or not) with the cut-off of ADP levels of $3.15 \mu \mathrm{g} / \mathrm{dL}$ with value $7.187(\alpha=0.05$, df 1 and Standard deviation 3.841, $\mathrm{P}=0.007$ ) and risk estimate analysis showed an odd ratio of 2.77 , which means that COVID-19 patients with ADP levels of $<3.15 \mu \mathrm{g} / \mathrm{dL}$ had a 2.7 times higher chance to survive compared to those with the higher ADP levels (95\% CI 1.357 - 5.477).

ADP is a family of adipokine whose levels decrease with visceral fat accumulation.. ADP contributes to insulin sensitivity, fatty acid oxidation, and diminution of gluconeogenesis pathways. ADP stimulate the Th1 polarization thus has a role in the antiviral inflammation.(18) in the condition of abdominal obesity, there was an unbalanced of leptin production and low-grade inflammation at the expense of ADP or lipocalin-2.(19) Ang1-7 has an active role in regulating the effects of adipokines, reciprocally, ADP attenuates Angiotensin II, which is increased as the effect of SARS-COV-2 binding to ACE2 receptor. Ang 1-7's role as a strong capillary barrier and anti-oxidative profile is altered in patients with visceral fat activation and could help to prevent ARDS.(20) ACE2 receptor deficiency also could become another underlying reason in the inflammatory condition of patients with lipid dysregulation and may interfere with the COVID-19 patients outcome. ACE2 receptor deficiency and a higher titer of pro-inflammatory cytokines in mice with glucose intolerance was correlated to the meta-inflammation(20), 
suggesting that Ang1-7, ACE-2 and adipokines are reciprocally influencing the outcomes in COVID-19 patients relating to the lipid dysregulation. Therefore, a further study analyzing the ADP levels towards the COVID-19 outcome needs to be performed and elaborated to the extend of COVID-19 patients' waist circumference to describe visceral fat metabolism, ACE2 receptor expression and the Ang1-7 levels, and a serial measurement of ADP. A larger study sample size and multicenter study will also contribute to the significant result of this study field.

\section{Conclusion}

Median ADP levels in COVID-19 patients was $2.8 \mu \mathrm{g} / \mathrm{mL}$ (1.5-7.9) with mean of $3.28 \pm 1.36 \mu \mathrm{g} / \mathrm{mL}$. Cut-off value of ADP level $3.15 \mu \mathrm{g} / \mathrm{mL}$ (AUC ROC 0.378, $\mathrm{P}=0.048$, (CI $0.265-0.4910$ )) could not reliable to predict the MODs incidence and mortality in COVID-19 patients. ADP levels of COVID-19 patients with different range of BMI and ARDS stage were significantly different. The average length of stay was also significantly different by the increasing level of ADP in COVID-19 patients. Although ADP level could not predict the MODs and mortality, ADP level was significantly correlated to MODs and mortality in COVID-19 patients ( $\mathrm{P}=0.047$ and $\mathrm{P}=0.019$, respectively).

\section{References}

1. Guo YR, Cao QD, Hong ZS, Tan YY, Chen SD, Jin HJ, et al. The origin, transmission and clinical therapies on coronavirus disease 2019 (COVID-19) outbreak- A n update on the status. Mil Med Res [Internet]. 2020 Mar 13 [cited 2022 Jan 20];7(1):1-10. Available from: https://mmrjournal.biomedcentral.com/articles/10.1186/s40779-020-00240-0

2. Coronavirus disease (COVID-19) Situation Report-182.

3. Zhang J, Wang X, Jia X, Li J, Hu K, Chen G, et al. Risk factors for disease severity, unimprovement, and mortality in COVID-19 patients in Wuhan, China. Clin Microbiol Infect [Internet]. 2020 Jun 1 [cited 2022 Jan 20];26(6):767-72. Available from: http://www.clinicalmicrobiologyandinfection.com/article/S1198743X20302172/fulltext

4. Banerjee M, Gupta S, Sharma P, Shekhawat J, Gauba K. Obesity and COVID-19: A Fatal Alliance. Indian J Clin Biochem [Internet]. 2020 Oct 1 [cited 2022 Jan 20];35(4):410-7. Available from: https://link.springer.com/article/10.1007/s12291-020-00909-2

5. Monteiro R, Azevedo I. Chronic inflammation in obesity and the metabolic syndrome. Mediators Inflamm [Internet]. 2010 [cited 2022 Jan 20];2010. Available from: https://pubmed.ncbi.nlm.nih.gov/20706689/

6. Goossens GH, Dicker D, Farpour-Lambert NJ, Fruhbeck G, Mullerova D, Woodward E, et al. Obesity and COVID-19: A Perspective from the European Association for the Study of Obesity on Immunological Perturbations, Therapeutic Challenges, and Opportunities in Obesity. Obes Facts [Internet]. 2020 Oct 1 [cited 2022 Jan 20];20(4):1. Available from:/pmc/articles/PMC7490508/

7. Robba C, Battaglini D, Pelosi P, Rocco P. Multiple organ dysfunction in SARS-CoV-2: MODS-CoV-2. Expert Rev Respir Med. 2020 Jun 22;14:1-4.

8. Shehzad A, Iqbal W, Shehzad O, Lee YS. Adiponectin: Regulation of its production and its role in human diseases. Horm 2012111 [Internet]. 2012 Feb 15 [cited 2022 Jan 20];11(1):8-20. Available from: https://link.springer.com/article/10.1007/BF03401534

9. World Health Organization. International Guidelines for Certification and Classification (Coding) of Covid-19 as Cause of Death. Who [Internet]. 2020;(April):14. Available from: https://www.who.int/classifications/icd/Guidelines_Cause_of_Death_COVID-19.pdf

10. Cao Y, Yang T, Yu S, Sun G, Gu C, Yi D. Relationships of adiponectin with markers of systemic inflammation and insulin resistance in infants undergoing open cardiac surgery. Mediators Inflamm. 2013;2013.

11. Di Filippo L, De Lorenzo R, Sciorati C, Capobianco A, Lorè NI, Giustina A, et al. Adiponectin to leptin ratio reflects inflammatory burden and survival in COVID-19. Diabetes Metab [Internet]. 2021 Nov 1 [cited 2022 Jan 21];47(6). Available from: https://pubmed.ncbi.nlm.nih.gov/34333093/

12. Poehls J, Wassel CL, Harris TB, Havel PJ, Swarbrick MM, Cummings SR, et al. Association of adiponectin with mortality in older adults: The Health, Aging, and Body Composition Study. 
Diabetologia. 2009;52(4):591-5.

13. Pajvani UB, Scherer PE. Adiponectin: Systemic contributor to insulin sensitivity. Curr Diab Rep [Internet]. 2003 [cited 2022 Jan 21];3(3):207-13. Available from: https://utsouthwestern.pure.elsevier.com/en/publications/adiponectin-systemic-contributor-to-insulinsensitivity

14. Simons PJ, van den Pangaart PS, Aerts JMFG, Boon L. Pro-inflammatory delipidizing cytokines reduce adiponectin secretion from human adipocytes without affecting adiponectin oligomerization. J Endocrinol [Internet]. 2007 Feb [cited 2022 Jan 21];192(2):289-99. Available from: https://joe.bioscientifica.com/view/journals/joe/192/2/1920289.xml

15. Hillenbrand A, Xu P, Zhou S, Blatz A, Weiss M, Hafner S, et al. Circulating adipokine levels and prognostic value in septic patients. J Inflamm (Lond) [Internet]. 2016 Sep 6 [cited 2022 Jan 21];13(1). Available from: https://pubmed.ncbi.nlm.nih.gov/27601939/

16. Kearns SM, Ahern KW, Patrie JT, Horton WB, Harris TE, Kadl A. Reduced adiponectin levels in patients with COVID-19 acute respiratory failure: A case-control study. Physiol Rep [Internet]. 2021 Apr 1 [cited 2022 Jan 21];9(7):e14843. Available from: https://onlinelibrary.wiley.com/doi/full/10.14814/phy2.14843

17. Caterino M, Gelzo M, Sol S, Fedele R, Annunziata A, Calabrese C, et al. Dysregulation of lipid metabolism and pathological inflammation in patients with COVID-19. Sci Reports 2021111 [Internet]. 2021 Feb 3 [cited 2022 Jan 21];11(1):1-10. Available from: https://www.nature.com/articles/s41598-02182426-7

18. Fang H, Judd RL. Adiponectin Regulation and Function. Compr Physiol [Internet]. 2018 Jul 1 [cited 2022 Jan 21];8(3):1031-63. Available from: https://onlinelibrary.wiley.com/doi/full/10.1002/cphy.c170046

19. Lelis D de F, Freitas DF de, Machado AS, Crespo TS, Santos SHS. Angiotensin-(1-7), Adipokines and Inflammation. Metabolism. 2019 Jun 1;95:36-45.

20. Méry G, Epaulard O, Borel A-L, Toussaint B, Le Gouellec A. COVID-19: Underlying Adipokine Storm and Angiotensin 1-7 Umbrella [Internet]. Vol. 11, Frontiers in Immunology . 2020. Available from: https://www.frontiersin.org/article/10.3389/fimmu.2020.01714 